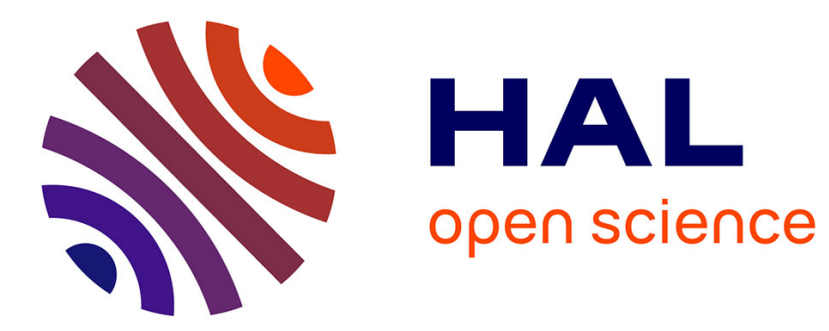

\title{
Building a Network of SME for a Global PSS Infrastructure in Complex High-Tech Systems: Example of Urban Applications
}

\author{
Alan Lelah, Fabrice Mathieux, Daniel Brissaud
}

\section{- To cite this version:}

Alan Lelah, Fabrice Mathieux, Daniel Brissaud. Building a Network of SME for a Global PSS Infrastructure in Complex High-Tech Systems: Example of Urban Applications. 3rd CIRP International Conference on Industrial Product Service Systems 2011, May 2011, Braunschweig, Germany. pp.344350, 10.1007/978-3-642-19689-8_60 . hal-00630710

\section{HAL Id: hal-00630710 https://hal.science/hal-00630710}

Submitted on 10 Oct 2011

HAL is a multi-disciplinary open access archive for the deposit and dissemination of scientific research documents, whether they are published or not. The documents may come from teaching and research institutions in France or abroad, or from public or private research centers.
L'archive ouverte pluridisciplinaire HAL, est destinée au dépôt et à la diffusion de documents scientifiques de niveau recherche, publiés ou non, émanant des établissements d'enseignement et de recherche français ou étrangers, des laboratoires publics ou privés. 


\title{
Building a Network of SME for a Global PSS Infrastructure in Complex High-Tech Systems: Example of Urban Applications
}

\author{
Alan Lelah¹, Fabrice Mathieux ${ }^{1}$, Daniel Brissaud ${ }^{1}$ \\ ${ }^{1}$ G-SCOP Laboratory, Grenoble University, Grenoble, France
}

\begin{abstract}
While small dynamic firms propose PSS applications based on new technologies quite easily, large infrastructures are often required. SMEs don't have the capacity to do this alone. For complex systems, different SMEs combine efforts to build an efficient infrastructure. Other SMEs can join and propose other PSS, creating a network. As networks grow the SMEs must understand their place within the structure and how they interact with other members. A tool is proposed to visualize relations between partners and illustrate the construction of the service chains composing the PSS. The tool is then applied to the case of urban PSS.
\end{abstract}

\section{Keywords:}

Network of SME, PSS Organization, Machine-to-Machine Application

\section{INTRODUCTION}

The search for more sustainable models of society has lead to the introduction of Product-Service Systems into Industry (PSS or IPS $^{2}$ ). PSS "consists of a mix of tangible products and intangible services designed and combined so that they jointly are capable of fulfilling final customer needs", [1]. Product-based services are an alternative to simply selling products. The responsibility of the producer is extended into anything between simply adding services to the sale of functionalities [1]. The movement towards dematerialization is amplified with the opportunities opened out by Information and Communication Technologies (ICT) [2] capable of providing monitoring systems allowing real-time adaptation of services and facilitating maintenance. Dynamic high-technology Small and Medium Enterprises (SME) propose innovative services and adapt to evolving demands very quickly. However their small size sometimes makes it difficult to penetrate public or other big markets. At the same time, with growing numbers of complex services, there is a move towards service infrastructures [3] with multiple actors involved, leading to complex organisations of supply chains. One solution is that a larger firm, an operator-integrator, proposes and operates this kind of infrastructure integrating products and services provided by a network of SME partners. This enables the combination of strong well-established operatorintegrators together with the flexibility and competitiveness of the SMEs. However it is necessary to understand the relations between the actors if the SMEs want to have their say and not be relegated to simple subcontractors of the operator-integrators. The partnership should benefit from the diversities of the SMEs and their dynamics without being tied down to the red tape of big operatorintegrators pushing for slowly matured replies to market change.

This article seeks to clarify the relative positions of the actors: amongst the SMEs themselves, and with the operator-integrator. After this introduction the transformation from vertical services to a horizontal service infrastructure will be described in more detail along with the organisational problems that are posed. Then a representation of the service-oriented architecture showing how the SMEs interact with one another and the operator-integrator will be described. In the next section the model will be applied to an example of an urban service showing how the representation would penetrate the complexity of the situation and the links between the actors will be described.

\section{ORGANISATION FOR GLOBAL INFRASTRUCTURE}

\subsection{From Vertical Services to a Global Infrastructure}

The transformation from direct vertical services provided by different operators or SMEs to a global infrastructure calling on a network of actors is described in Figures 1 and 3. Figure 1a shows an initial service provider (ISP) that provides vertical services to a population $(P)$. The services are vertical as they support just one specific service.

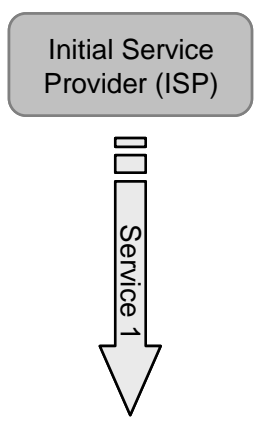

Population (P)

(a) Vertical service

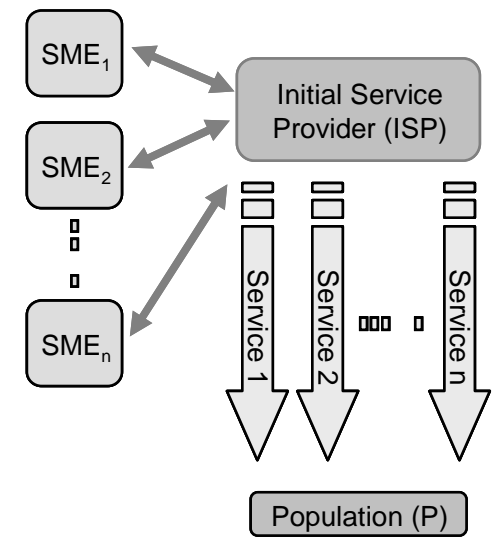

(b) Service Provider - SME relations
Figure 1: Vertical Services.

Examples of the couple initial service provider-population could be a local town council providing services to its citizens; a hospital providing heath services to its patients; or a truck vendor supplying a fleet of vehicles to industrials. Today, many of these services are 
high-technology applications and the initial service provider may have neither all the competences internally nor have the intention to acquire these competences. In this case the initial service provider would turn to an SME that can bring skills and know-how to provide the service directly to the population concerned, or through the initial service provider. For example in a truck-vending IPS ${ }^{2}$ the injectors could be supplied by a SME. The life-cycle of the injectors is very much shorter than the life-cycle of the truck and it is environmentally interesting to replace used injectors with remanufactured ones [4]. This could be a good case of PSS as the SME would replace a faulty injector and remanufacture the old one. In the same way, another SME could, for example, deal with the tyres or propose other complementary services. The number of IPS $^{2}$ calling on different SMEs can rapidly become significant. This may lead to the situation shown in Figure $1 \mathrm{~b}$. The initial service provider now has to deal with a multitude of SMEs, each proposing a different service.

Another evolution today improves IPS 2 with ICT [2]. For example in the case of the gear-box the SME providing the IPS ${ }^{2}$ could use Machine-to-Machine (M2M) communication [5] to monitor the gearbox in the trucks wherever the trucks may be. M2M communication here means that some sensors are placed in the gear-box and measure relevant parameters like oil, temperature, wear, etc. The sensors are equipped with a communication system sending the measures regularly to a central managing system in the truck. In turn this system would relay the important information via GSM, through the telecommunication network and finally to a service platform of the SME. This is called M2M because up to the service platform no human intervention is necessary. The machines (sensors, command unit, telecom network and service platform) communicate with one another. At the end of the line, the SME can access real-time knowledge of the functioning of the gear-box PSS, adapting the service or facilitating intervention in case of need. The M2M infrastructure is shown in Figure 2.

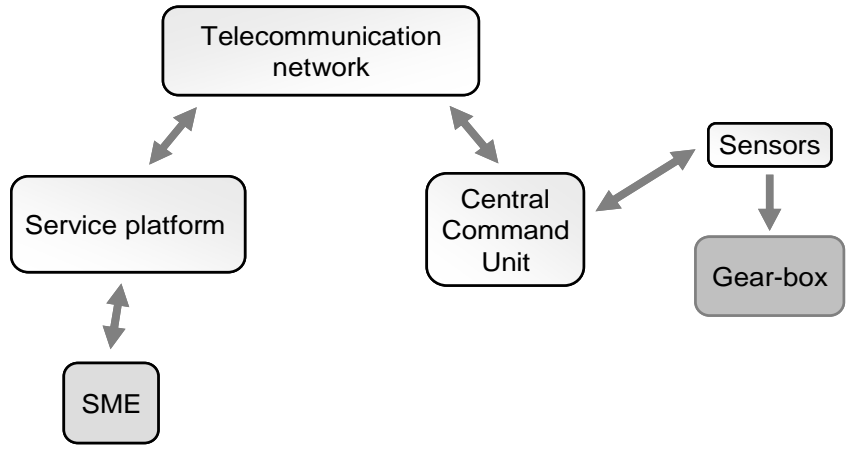

Figure 2: M2M communication.

However, the system can get more complex. The SME that manufactures the gear-box may not be competent in M2M and could turn to another SME who would provide the M2M PSS infrastructure, and so on. Along with the multiplication of services we will soon end up with a complicated network of SMEs and the risk that different infrastructures concurrence each other. A part from a problem of sustainability that would arise, the infrastructures could start to interfere technically with one another. At one time it would become interesting that the vertical services running in parallel make use of a common service infrastructure (Figure 3).

A new organisation would be set up. The different SMEs would form a network, together with a pertinent operator-integrator $(\mathrm{Ol})$ who would be the natural leader of the group. The initial service provider will only have one interlocutor to speak to and will not have to worry about problems linked to new SMEs joining the group or old ones leaving. All this would be done by the operator-integrator who will insure the continuity and the coherence of the group. A good example of such a network is SensCity [3,6], a French project for a global infrastructure of services in urban areas.

Organisational problems are now transferred to the network of SMEs and the operator-integrator. Even though the know-how of the operator-integrator is more adapted to the core question, the organisation of such a network can become quite complicated and it would be important to distinguish the different relations between the actors.

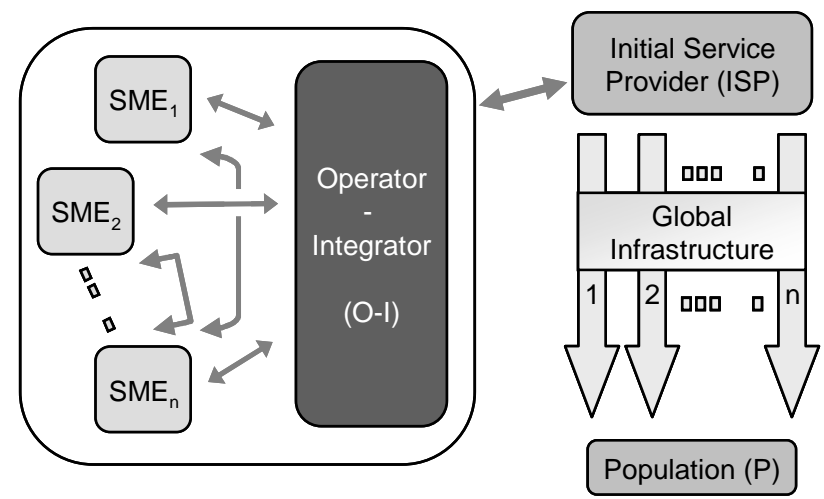

Figure 3: Horizontal services with a global service infrastructure.

\subsection{Models for the Organization of PSS}

Shostack [7] proposed service blueprints to facilitate the design of services. A line of visibility differentiated what the customer perceived of the more complicated operations necessary to operate the service. Shimomura et al. [8] extended this notion for the case of PSS in order to integrate both the product and the service. Maussang et al. [9] described a PSS as being a set of service units and physical objects, while Tomiyama [10] declared that artefacts were usually service channels or service contents. These representations were very efficient for modelling complex services. However they did not clearly describe the organisation of the service between the actors. It was not always easy to identify the actor that provided each service and the actor or client that received the service.

We proposed a similar diagram in which the accent was placed on the relations between partners more than the details of the service and its physical support [11]. However in the case of services providing channels it is not always clear who commands what service. A modified model is therefore proposed to distinguish services providing channels from services providing contents.

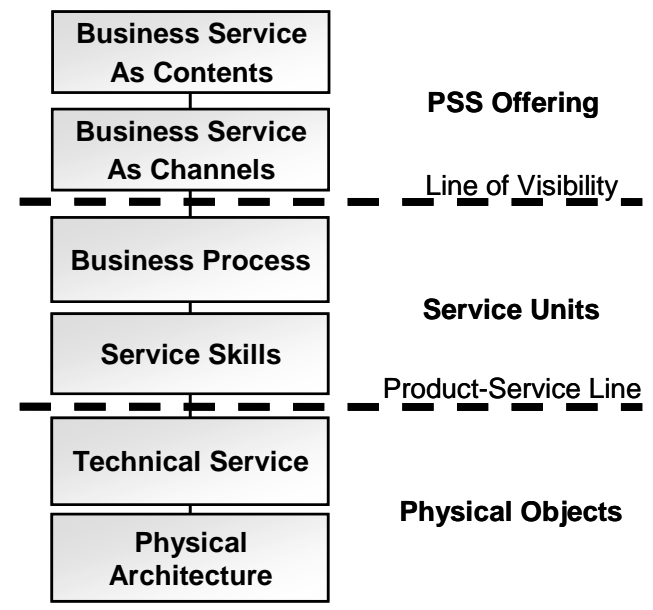

Figure 4: Service offering; service; physical representation. 
Basically, in the modified model, above the line of visibility, the PSS offering is proposed by a provider to a receiver. It describes the business service as experienced by the client or partner. The receiver requires a service and turns to the provider who supplies the service. The PSS offering must satisfy the needs of the receiver. Services providing channels and service providing contents are distinguished in two different levels, as shown in Figure 4.

Below the line of visibility, the organisation of the PSS offering is structured and service units are distinguished from physical objects. The product-service line expresses the need for business skills and technical skills to fulfil the PSS. The business skills correspond to the service units of the PSS. A business process must be established and service skills needed to perform the service are associated. The service units rely on physical objects to operate. At the lowest level, the physical architecture of the system is made of the different objects that form it. Technical skills are necessary to run the system and reply to service demands.

In order to fulfil certain aspects of the service, the provider may call on to another SME who will take care of a part of the service, and so on. This is represented in the Figure 5 with arrows showing solicitation of new services from other SMEs. On the left the population $(P)$ solicits the final service. The initial service provider (ISP) solicits two SME. SME1 provides a channel and SME2 provides contents through the channel. SME2, in turn, solicits another service (not shown in the figure).

\section{ISP}

SME1

SME2

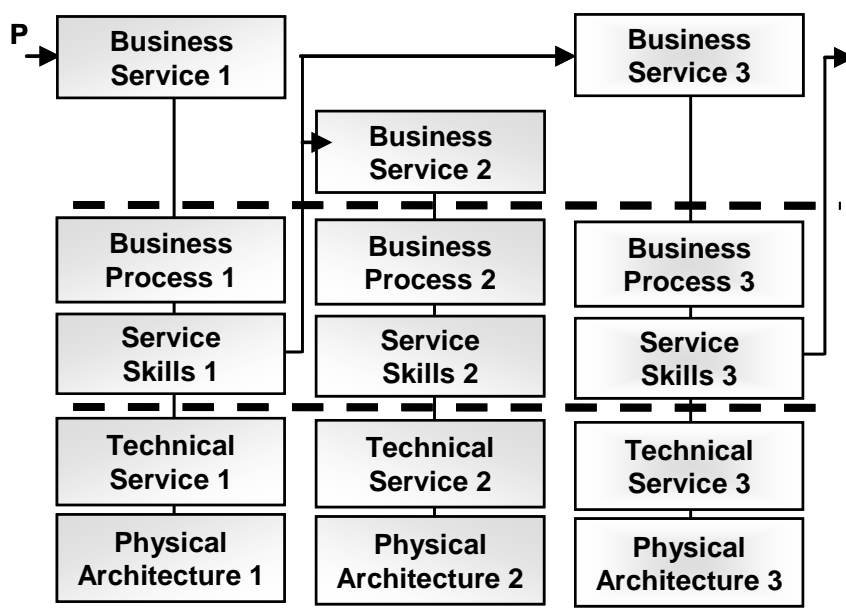

Figure 5: Successive providers.

\section{APPLICATION TO AN INFRASTRUCTURE FOR URBAN SERVICES}

Local public authorities provide glass waste collection facilities for the residents of an agglomeration of towns. An SME then proposes a service to optimise collecting the cullet. Finally a network of SMEs, together with a telecom operator proposes an infrastructure for urban services. Our initial SME with its' optimisation of glass waste collection now forms part of the network. In this section we will use the proposed model to describe the different situations.

\subsection{Waste Glass Collection}

The local public authorities insure the collection of waste glass through a waste collection service. Waste-banks are installed for residents to dispose their waste glass. The glass is collected in bins that are emptied by trucks going on regular rounds. In the classical service the trucks systematically run through the waste-bank park looking for bins that are sufficiently full.

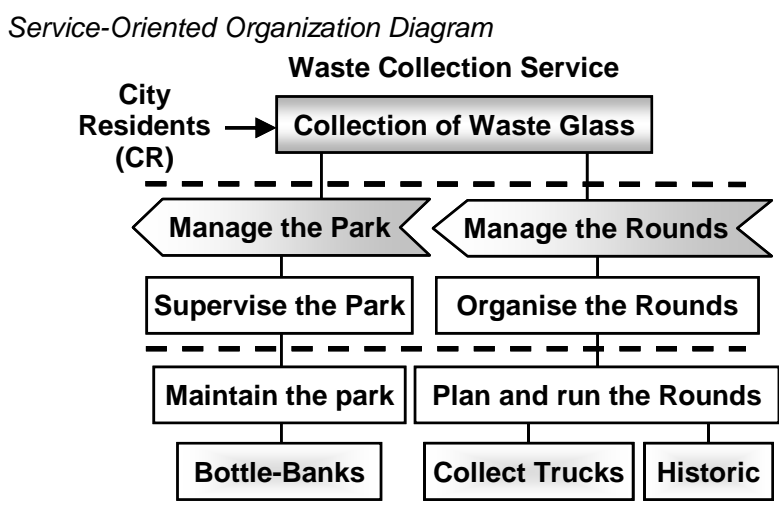

Figure 6: Urban Waste Glass Collection.

The service is represented in Figure 6. As the service is basic and requires no service channel, the top level does not have to be split in two for channel and content services. The population concerned by the service is the city residents $(C R)$ and the initial service provider is the waste collection service run by the public authorities. There are basically two major business processes in the service: managing the park and managing the rounds. Arrow-shaped boxes have been used to show successive stages of the overall business process provided by the waste collection service. In this case they indicate that In order to manage the park, the rounds have to be managed. Managing the park signifies supervising the park and the corresponding technical service concerns the maintenance of the bins in the bottle-banks. Managing the rounds implies the organization of collection rounds and technically running the trucks and stocking the history of the rounds. The public authorities provide the service alone.

\subsection{The M2M-Enhanced Vertical Application}

In the next step a SME proposes an optimization process for the truck rounds making use of sensors in an M2M network [12,13].

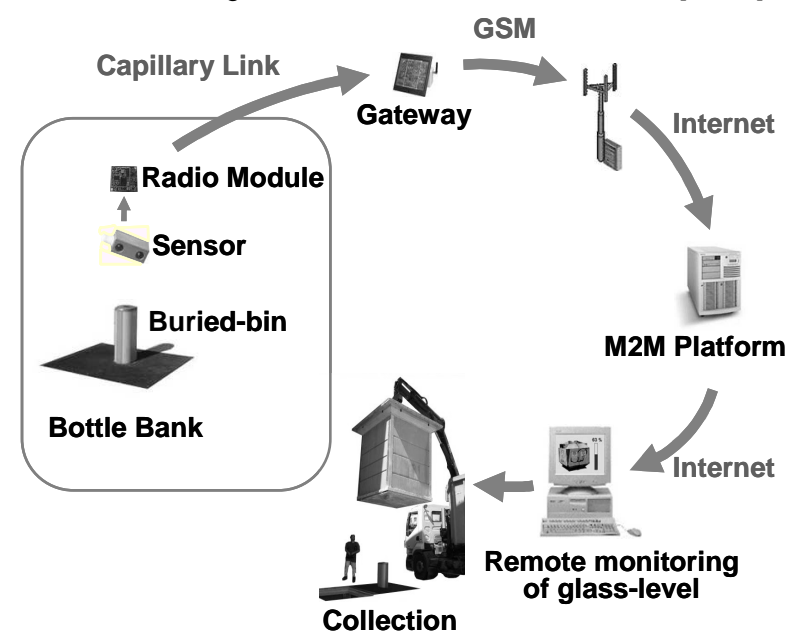

Figure 7: M2M-enhanced waste glass collection.

Figure 7 resumes the service. In the bottle-banks, the bins have embedded ultrasonic sensors that measure the glass levels every day. The sensors are coupled to communication modules that send the information to gateways in the proximity of the banks. In this way the whole park is covered and the data collected is relayed via the telecom network to an urban service platform. Here, the information is treated to optimize the collection of the glass and the results are then sent on to the waste collection service run by the local authorities. The complete service is provided for the local 
authorities by a single SME. Organization is straightforward: the data is treated within the SME.

\section{Service-Oriented Organization Diagram}

Figure 8 depicts the situation. It shows how the SME is solicited by the waste collection service run by the local authorities in order to satisfy the needs of the city residents. Communication between the SME and the waste collection service is done by internet connexions and the two entities must solicit a telecom operator. The SME organizes the waste collection. This means optimizing the rounds using a service platform server. The optimization requires daily information on the glass-levels. The SME must monitor the glass-levels. Technically it is necessary to plan the measures and collect the data. Additionally, server operation and support have to be insured. The SME needs to use classical telecom services of GSM and IP connection to collect the glass level data measured in the bottle-banks. On the field the SME would manage the sensor network with the gateways and insure correct functioning of the park. The ICT services are solicited only as service channels that transfer data between the gateways and the service platform server and then between the SME and the local authorities. The diagram shows the solicitation of ICT services by the SME as well as by the local authorities.

\subsection{A Global Urban M2M Infrastructure}

\section{An Urban M2M Infrastructure}

Vertical applications are relatively easy to build by innovative SMEs, but they are not so efficient in terms of resources. Other than the problem of piling up sensor network structures coming from different applications, the SME must take care of the whole service and installs its own sensor network. It has to use the telecom network as a simple client with no possibility to guarantee QoS in the case of network failure. In addition, the SME has to support maintenance in different towns and even in different countries. It has been proposed [3] to set up an infrastructure to support M2M sensor-enhanced services in urban areas. The infrastructure is built by a consortium of SMEs together with a telecom operator. The telecom operator brings his know-how and reputation making the consortium a natural partner to work with municipalities or other local authorities. The size and the stature of the telecom operator is a guarantee of the sustainability of the consortium. The local authority will only need to deal with the telecom operator representing the consortium and the consortium as a whole will take on the role of insuring that new members proposing new or better applications can join and that leaving members will be replaced when necessary.

Waste Collection Service

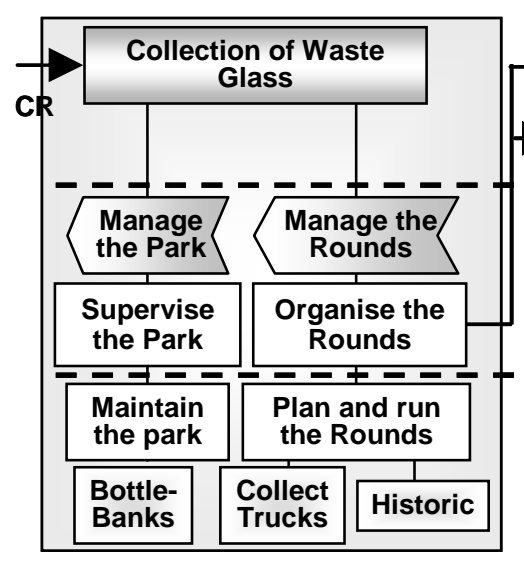

Telecom operator

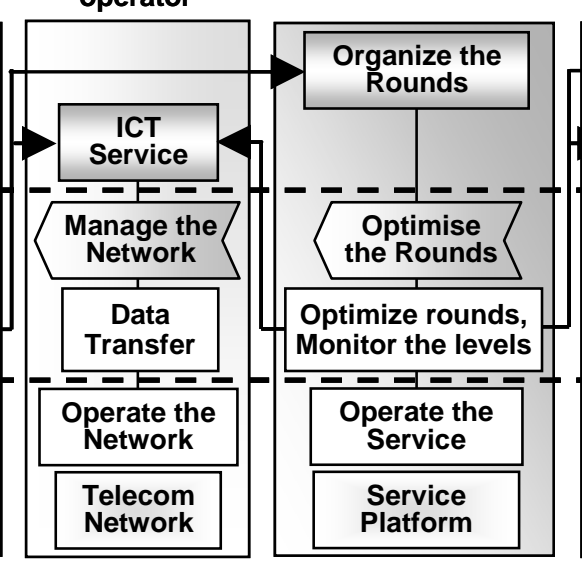

SME
Within the consortium, some SMEs will provide sensors to collect data in the perimeter covered by the infrastructure. The variety of applications proposed to the local authorities will come from their dynamism. Some of these SMEs will provide their own applications while others would just transfer the data collected to specialized SMEs providing a panoply of services. Yet others will deal with the local M2M wireless communication, including the protocols and insuring the evolution of these technologies in open state-of-the-art standards. Specialized SMEs will provide gateway coverage for all the networks, and when necessary, complete the gateways with repeaters to collect data when it is more convenient.

Other SMEs will be involved with the functioning of an urban service platform. The platform will collect and control the data coming from the sensor network; stock and manage the data; deal with brokerage and other legal questions concerning the access to the information and finally sending information to the end-users or other servers dealing with specific applications.

\section{Service-Oriented Organization Diagram}

The organization has now become quite complex to manage and the service-oriented organization diagram can help clarify the relations between the different partners. The case of waste glass collection is shown in figure 9 . The infrastructure can be considered as imbrications of successive B2B services. As before, the waste collection service asks the service providing SME to help optimize the collection rounds for the park of bottle-banks in order to satisfy the needs of the city residents. The telecom IP network serves as a channel to exchange data, while the service provider needs to monitor the glass levels in order to run the optimization. This time the service provider will turn to the urban platform host, shown in the diagram just as one entity for simplification. In reality there will be many SMEs working on different parts of the platform (data control, data management, brokerage, etc.) but they will not be considered here. Other service providers can also address the platform. They may offer other applications like providing information on pollution. They are not shown in the figure either. The telecom operator is always seen as a channel for data transfer. However, in the organizational choice described in the figure, the gateway operator is considered as a content provider. In addition to providing a simple gateway, it also manages the sensors and plays a role in stocking information. It can collect data at different moments to be combined and sent together. The gateway operator is thus solicited by the urban platform host to manage the sensors and in turn solicits the different sensor operators in order to collect measured data.

Figure 8: SME service-provider for glass waste collection.

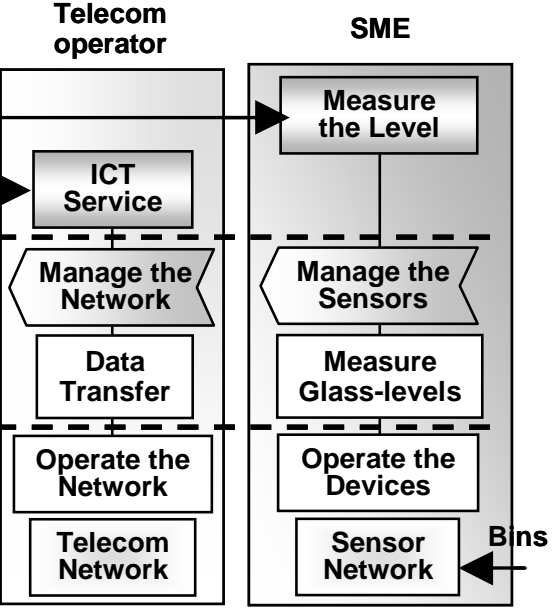



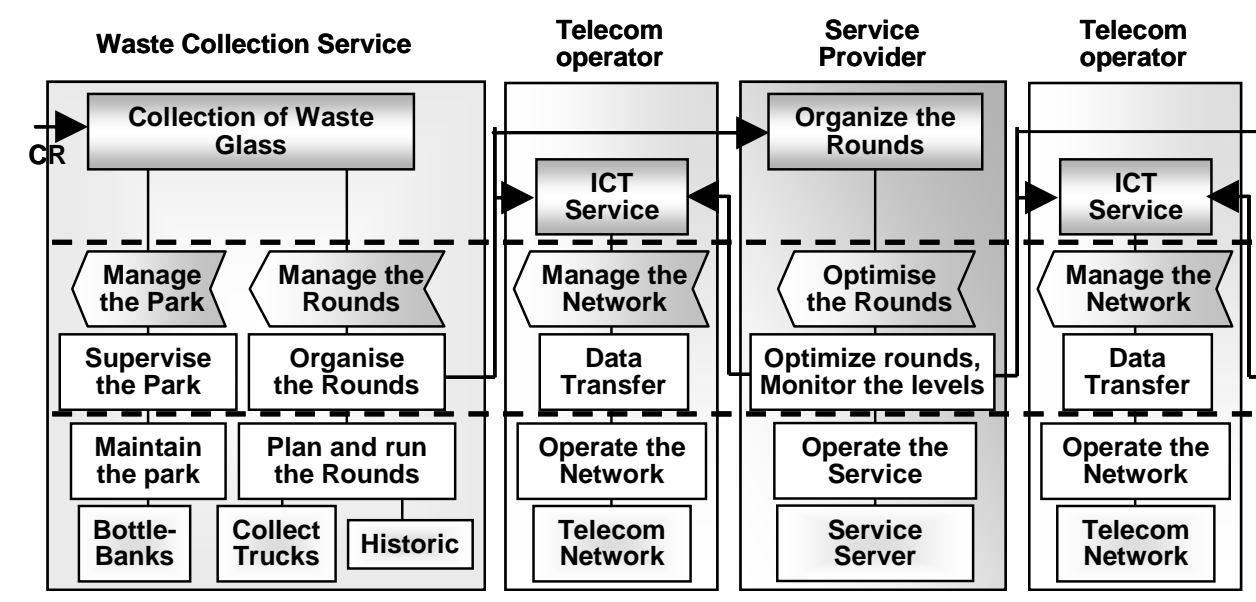

Urban Platform Host

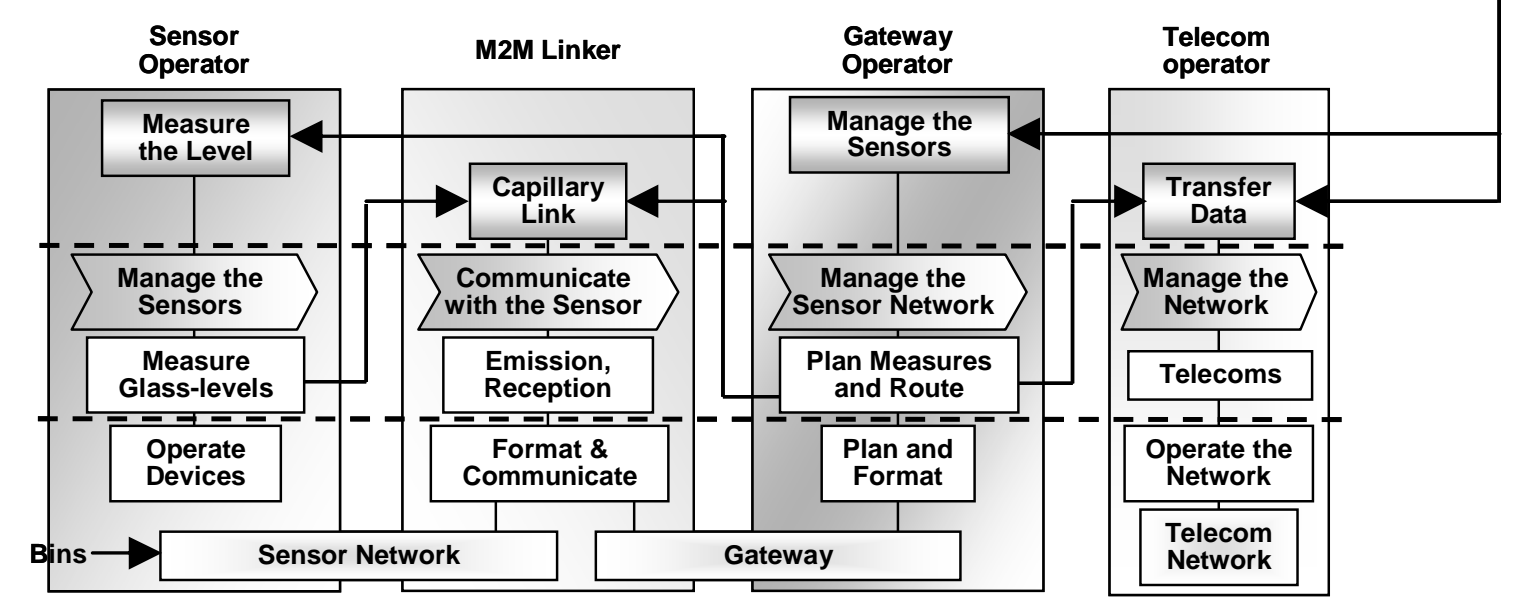

Figure 9: M2M-enhanced PSS network.

Of course the full process is more complicated and the schema has been simplified in order to give an overall view.

\section{Alternative Scenario}

However this is not the only organization possible. Another scenario of organization that can be proposed is shown in figure 10. Here the gateway is considered as a service channel and does not take part in managing the sensors. In this case the gateway operator is solicited by both the SME sensor operator and the telecom operator to relay information. In this scenario, the urban platform directly manages the different sensor networks and takes charge of the collection. The relations between the different SMEs and the telecom operator have changed and the repartition of work done by each actor is modified even though the overall workload is the identical.

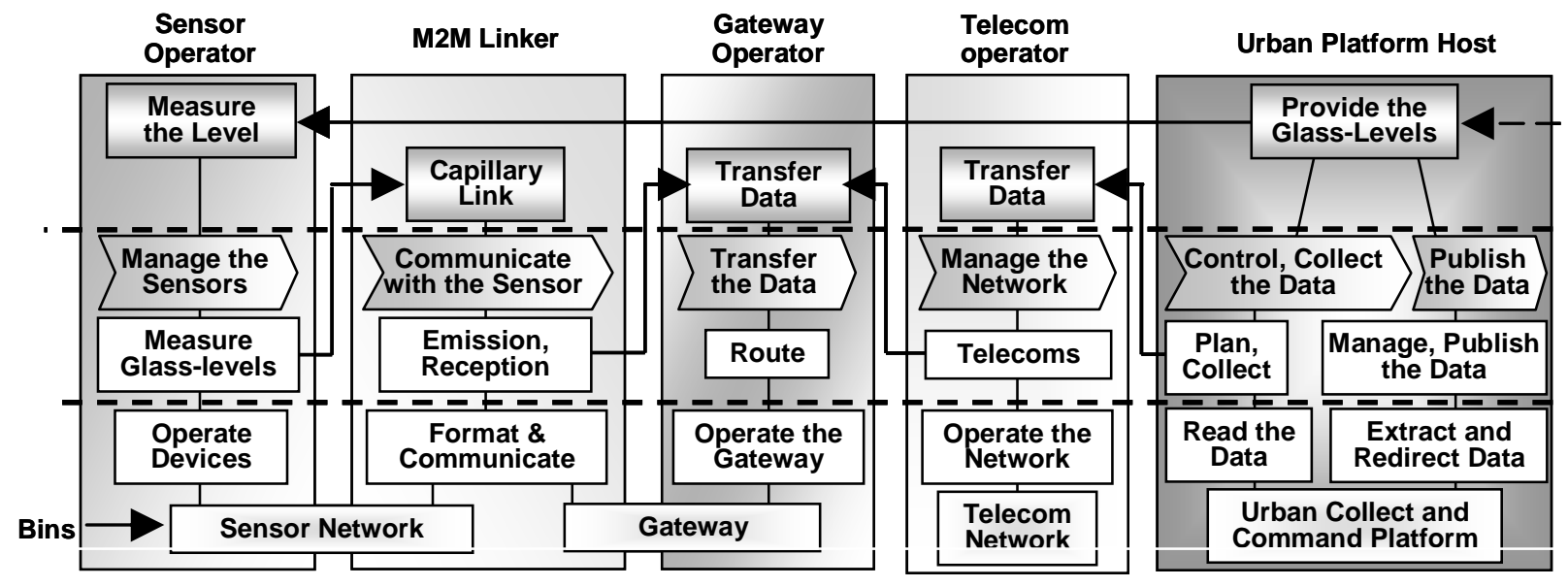

Figure 10: Alternative Scenario. 


\section{CONCLUSION}

A service-oriented organization diagram for a network of SMEs together with an operator-integrator has been proposed. It helps clarifying the passage from vertical services to an infrastructure for PSS in different environments. The diagram was applied to the French project SensCity proposing an infrastructure for M2M-enhanced urban services. The case of glass waste collection showed the different organizational transformations involved in the passage from the basic service to a vertical M2M service and finally to a mutualised infrastructure for services in the city. The diagram was also used to discuss the implications of a possible alternative scenario within the consortium.

\section{ACKNOWLEDGMENTS}

The authors would like to thank Lucien Vincent and Xavier Boucher, LSTI, as well as Claude Pellegrin, COACTIS, and other participants of the GOSPI cluster in the Rhone-Alps region for the interesting debates that led to the elaboration of the diagrams representing service relations used in this article. We have presented a network of complementary SMEs lead by an operator integrator to provide a global infrastructure for urban services.

\section{REFERENCES}

[1] Tukker, A., Tischner, U., (2006): Product-services as a research field: past, present and future. Reflections from a decade of research, in Journal of Cleaner Production, 14(17), pp. 1552-1556.

[2] Heiskanen, E., Halme, M., Jalas, M., Kärnä, A., Lovio, R., (2001): Dematerialization: The Potential of ICT and Services, Ministry of Environment, Helsinki.

[3] Lelah, A., Mathieux, F., Brissaud, D., Gimeno, V. (2010): SensCity: a new project opening the way for sustainable services in the city based on a mutualised M2M infrastructure, in Proceedings of the 2nd CIRP IPS² Conference, pp. 99-106, Linköping, Sweden.
[4] Amaya, J., Zwolinski, P., Brissaud, D., (2010): Environmental benefits of parts remanufacturing: the truck injector case, in Proceedings of the 17th CIRP International Conference on Life Cycle Engineering, Hefei, China

[5] Orange, FING, Syntec Informatique (2006): White paper Machine To Machine, stakes and prospects, France.

[6] SensCity, http://senscity.minalogic.net

[7] Shostack, G. L., (1987): Service Positioning Through Structural Change, in Journal of Marketing, 51, pp. 3443.

[8] Shimomura, Y., Hara, T., Arai, T., (2009): A unified representation scheme for effective PSS development, in CIRP Annals - Manufacturing Technology, 58(1), pp. 379-382.

[9] Maussang, N., Zwolinski, P., Brissaud, D., (2009): Product-service system design methodology: from the PSS - architecture design to the products specifications, in Journal of Engineering Design, 20(4), p. 349

[10] Tomiyama, T. (2001): Service engineering to intensify service contents in product life cycles, in Proceedings of EcoDesign 2001 pp. 613-618, Tokyo, Japan.

[11] Lelah, A., Mathieux, F., Brissaud, D., Vincent, L., (2010): A Network of Complementary SMEs for a Global Infrastructure for Services: the Example of Environmental Urban Services, in Proceedings of Prove 2010, pp. 73-80, St. Etienne, France.

[12] BH Environnement, http://www.bhenvironnement.com/

[13] Houang, T., Lelah, A., Mathieux, F., Brissaud, D., Gimeno, V. (2010): Environmental Evaluation of Machine-to-Machine Services: the case of Glass Waste Collection, in Proceedings of the 2nd CIRP IPS² Conference, pp. 75-82, Linköping, Sweden. 